\title{
Responsabilidade Social Empresarial: Uma Análise sobre a Correlação entre a Variação do Índice de Sustentabilidade Empresarial (ISE) e o Lucro das Empresas Socialmente Responsáveis que compõem esse Índice ${ }^{1}$
}

\author{
Fabrício Alves de Sousa ${ }^{2}$ \\ Lúcia Silva Albuquerque ${ }^{3}$ \\ Thaiseany Freitas Rêgo ${ }^{4}$ \\ Marconi Araújo Rodrigues ${ }^{5}$
}

\section{RESUMO}

Quando se trata de Responsabilidade Social no ambiente corporativo, a questão econômico-financeira é algo que não se pode deixar de lado nas discussões, por esse motivo, saber se as atitudes sociais adotadas pelas organizações podem ou não gerar um melhor resultado financeiro torna-se uma constante. Pensando na atitude da BM\&FBOVESPA em criar o Índice de Sustentabilidade Empresarial (ISE), no qual se agrupam as empresas que mais se destacam na área social e ambiental em uma carteira de investimentos capaz de evidenciar financeiramente o retorno de suas operações financeiras e econômicas este trabalho visa demonstrar o desempenho dessas empresas e apontar qual o grau de correlação entre suas receitas líquidas e o ISE no período em que as mesmas fizeram parte da carteira entre 2005 a 2009. Para isso o presente trabalho, utilizou-se da análise de regressão e correlação cujo método utilizado foi a Regressão Simples, não linear procurando descrever e compreender a suposta existência de relacionamento entre essas variáveis. Os resultados obtidos apontaram que um ano após o ingresso das empresas na carteira do ISE, em 2007, suas receitas líquidas aumentaram $56,46 \%$ em relação ao ano anterior, e a carteira do ISE aumentou no mesmo período 40,35\%, e através da análise de regressão, verifica-se que $86,9 \%$ das variações do ISE são explicadas pela variação nos resultados da carteira, ou seja, quanto mais varia o ISE, mais as receitas líquidas das empresas variarão respectivamente no percentual declarado.

Palavras-chave: Responsabilidade Social Empresarial. Índice de Sustentabilidade Empresarial. Receita líquida.

\begin{abstract}
When it comes to social responsibility in the corporate environment, the financial-economic question is something that can not be set aside in the discussions, therefore, whether the attitudes adopted by social organizations may or may not generate a better financial result becomes a constant. Thinking about the attitude of the BM\&FBOVESPA to create the Corporate Sustainability Index (ISE), which are grouped the companies that stand out in the social and environmental performance in a portfolio can demonstrate a financial return on its financial and economic this job aims to demonstrate the performance of these companies and point out the degree of correlation between ISE and its net revenues in the period in which they were part of the portfolio between 2005 to 2009. For this, the present work, we used regression analysis and correlation whose method was the simple regression, nonlinear trying to describe and understand the supposed existence of the relationship between these variables. The results showed that a year after the entry of firms in the ISE portfolio in 2007, its net revenues increased $56.46 \%$ over the previous year, and the ISE portfolio increased $40.35 \%$ over the same period, and through regression analysis, it appears that $86.9 \%$ of the ISE variations are explained by variations in performance of the portfolio, that is, the more the ISE ranges, plus net receipts of companies respectively vary in the percentage declared.
\end{abstract}

Key- words: Corporate Social Responsibility. Corporate Sustainability Index. Net income.

\footnotetext{
${ }^{1}$ Artigo publicado nos anais do V ANPCONT, Vitória/ES, 2011.

${ }^{2}$ Graduado em Ciências Contábeis - UACC/CCJS - Universidade Federal de Campina Grande, e-mail: fabriciopop@ gmail.com.

${ }^{3}$ Professora da UACC/CCJS - Universidade Federal de Campina Grande, e-mail: luciasalbuquerque@ gmail.com

${ }^{4}$ Professora da UACC/CCJS - Universidade Federal de Campina Grande, e-mail: thaiseany@ yahoo.com.br

${ }^{5}$ Professor da UACC/CCJS - Universidade Federal de Campina Grande, e-mail: marconirodrigues@ gmail.com
} 


\section{INTRODUÇÃ̃O}

Não foram poucos os fatores que movimentaram as pessoas em busca de uma sociedade mais justa, Macedo e Aversa (2002) comentam que quando a Organização das Nações Unidas (ONU) instituiu o ano de 2001 como o Ano Internacional do Voluntariado, milhares de pessoas se mobilizaram, em todos os segmentos da sociedade brasileira com o objetivo de ajudar ao próximo em prol da causa social, comentando que a divulgação dessas ações sociais na mídia, fez com que a população intensificasse a discussão sobre novas maneiras de se lidar com os problemas sociais.

Segundo Milani Filho, Corrar e Andrade (2009, p. 153) "Os graves problemas sociais encontrados no panorama mundial evidenciam a ausência ou insuficiência de políticas governamentais eficientes e perenes capazes de proporcionar o bem-estar coletivo."

Diante da deficiência do Estado em suprir nossas severas demandas sociais, empresas atuam cada vez mais de forma proativa e incorporam um discurso social mais justo. Poder-seia dizer que o objetivo principal das empresas não é mais a obtenção de lucros, mas sim ajudar o próximo, no entanto, talvez seja um tanto quanto radical e muito provavelmente os empresários não abrirão mão de sua remuneração somente para ajudar o próximo.

Perottoni (2002, p 51) afirma que "A responsabilidade social da empresa está na sua participação direta nas ações da comunidade onde está presente [...], capacitando a empresa a crescer e a permanecer no mercado".

Ainda conforme esse autor, o fato de praticar ações sociais acarreta uma série de mudanças positivas na organização como a fidelidade dos clientes, a conquista de novos, facilita novas parcerias com outras empresas e fornecedores, gera reconhecimento da sociedade, melhora a imagem da empresa, valorizando sua marca além de aumentar o consumo e consequentemente suas receitas.

Significa dizer que é uma tendência as empresas adotarem posturas socialmente responsáveis, mostrando que é possível continuar auferindo lucros e proporcionar melhorias no meio em que está inserida e aos seus colaboradores.

Nesse sentido, Pinto e Ribeiro (2005, p. 38-39) acreditam que:

[...] a divulgação das ações sociais das organizações, dos planos internos voltados ao seu ativo humano, das políticas de investimentos direcionadas ao meio ambiente, da evidenciação da formação e distribuição da riqueza e contribuições a entidades assistenciais é de grande utilidade não somente para o público, mas também para a própria organização que as publica, haja vista que a publicação do balanço social, elaborado com informações fidedignas, é um instrumento que propicia um relacionamento mais íntimo com o público e, consequentemente, a melhoria da imagem da empresa, além de servir como instrumento de controle e avaliação aos gestores.

Por esses e outros motivos a BM\&FBOVESPA criou o Índice de Sustentabilidade Empresarial (ISE), com o intuito de selecionar as empresas que mais se destacam na área social e ambiental e agrupá-las em uma carteira de investimentos capaz de evidenciar financeiramente o retorno de suas operações financeiras e econômicas nas áreas em que atuam e principalmente nas áreas sócio-ambientais. Para Melo Neto e Froes (1999 apud OLIVEIRA; GOUVÊA; GUAGLIARDI 2004): 
A responsabilidade social empresarial é constituída por duas dimensões: a interna, que tem como público seus empregados e seus dependentes, e a externa, que tem como foco a comunidade, por meio de ações sociais voltadas principalmente para as áreas de educação, saúde, assistência social e ecologia.

Segundo a BM\&FBOVESPA (2010) a aposta do mercado financeiro é que em um futuro não muito distante essas ações se valorizem, a medida que as exigências por um mercado responsável se efetive, sendo assim, a tendência é de que as empresas que compõem este índice, desfrutem de maiores investimentos.

Com base no exposto e considerando o cenário vivenciado atualmente pelas empresas que precisam gerenciar as variáveis socioeconômicas, não apenas em cumprimento das obrigações legais, mas também como forma de aumentar a competitividade, e maior expectativa de lucro, esta pesquisa procura responder o seguinte questionamento: Existe correlação entre o ISE e os resultados líquidos das empresas que compõem esse índice, entre os anos de 2005 a 2009? Portanto, o objetivo da pesquisa é verificar se existe correlação entre o ISE e os resultados líquidos das empresas que compõem esse índice, entre os anos de 2005 a 2009.

\section{FUNDAMENTAÇÃO TEÓRICA}

\subsection{Responsabilidade Social}

Silva e Carvalho (2008) destacam que após a crise econômica de 1970 e os vários choques de recessão ocasionados pelo período inflacionário desestabilizou as economias ocidentais, o ápice ideológico sobre a função do Estado de Bem Estar em ser regulador social com ajustes da economia e da política, passou a ser questionado. O Estado até então, caracterizado como bem feitor, percebeu uma necessidade de mudar diante dessas crises, principalmente no plano das políticas sociais.

Segundo Alves (2002), o início dos anos 90 trouxe um grande paradoxo, pois simultaneamente ao processo de democratização das instituições, o Brasil viveu uma crise econômica - que se arrasta desde o final dos anos 70 - sem precedentes na sua história, elevando ainda mais a distância entre pobres e ricos. E, justamente nesse período de aumento das demandas sociais, enfrentou-se a hegemonia de um discurso neoliberal que pede uma redução do tamanho e das atividades do Estado, proclamando o "império do mercado". Diante desse fato, programas estatais de caráter social, que já funcionavam precariamente, tendem a desaparecer, o que com certeza agravará ainda mais essa situação.

Diante dessa realidade, a sociedade civil, como meio de responder às suas próprias demandas, organiza-se por meio de entidades sem fins lucrativos, angariando recursos no sentido de suprir necessidades coletivas. Ressalta-se que essas entidades são vistas, muitas vezes, como uma possibilidade de gerar auto-sustentação para as populações mais carentes e, assim, vêm aumentando seu poder de influência.

Esse fator foi condicionante para uma reação da sociedade em busca de melhores condições de vida. Surgiu então de uma nova ordem social formada por organizações não governamentais (ONGs), organizações da sociedade civil de interesse público (OSCIP), associações, Fundações, etc. São organizações sem fins lucrativos que objetivam promover o bem estar social em suas áreas de especialização, seja na educação, saúde, lazer etc. O termo "Terceiro Setor" é utilizado para diferenciar essas organizações daquelas do "setor privado" (segundo setor) e do "setor público" (primeiro setor). Tudo isso é fruto da onda liberal que se

REUNIR - Revista de Administração, Contabilidade e Sustentabilidade - Vol. 1, nº 1, p.52-68, Mai-Ago/2011. 
alastrou pelo mundo, cujas características são identificadas por Mello Neto e Froes (2001, p. $3)$ :

- Predomínio da ação comunitária sobre a ação estatal e empresarial;

- Mudanças profundas nas relações do cidadão com o governo;

- Surgimento de uma nova concepção de Estado;

- Substituição da prevalência dos interesses coorporativos pela hegemonia do interesse social;

- Surgimento de novas instituições sociais;

- Diminuição da influência da burocracia estatal e aumento da influência das entidades comunitárias;

- Abertura de novos canais de reivindicações sociais; e

- Emergência de redes de solidariedade social.

A sociedade percebe a importância de ajudar quem precisa, e fazer isso se tornou pratica constante, valendo de respeito e valorização perante a população.

Etimologicamente a palavra responsabilidade deriva do latim respondere, responder. É sobre esta perspectiva que o ícone das lutas pelas causas sociais, Herbert José de Souza, popularmente conhecido como "Betinho" formado em Sociologia e Política e de Administração Pública na Faculdade de Ciências Econômicas da Universidade de Minas Gerais, se engajou em lutas sociais e políticas, defendendo as classes sociais menosprezadas, e lutava contra a fome, o desemprego e outras causas.

Para o Prof. Carlos Fernandes, Universidade Federal de Campina Grande, (2010) Herbert de Sousa foi um dos primeiros intelectuais a advogar em favor das organizações nãogovernamentais, que não dependem do estado nem da iniciativa privada para se manter.

Após a realização de inúmeros projetos e de envolver os cidadãos na luta por uma sociedade mais justa, o setor econômico passa a se engajar aos poucos nessas causas em busca de reconhecimento pelo mercado consumidor. Nasce, portanto, um novo conceito: Responsabilidade Social Empresarial (RSE).

\subsection{Responsabilidade Social Empresarial}

Ashley (2002), após analisar diversos conceitos de responsabilidade social, concluiu que, em uma visão expandida, o termo refere-se a toda e qualquer ação empreendida por uma organização que contribua para a qualidade de vida da sociedade.

As constantes mudanças ocorridas nas últimas décadas relacionadas às questões sociais, às carências e desigualdades existentes no país e junte-se a isso as deficiências do Estado para suprir as demandas sociais, fazem com que as empresas direcionem estrategicamente seus objetivos e adotem medidas para melhorar o bem estar social, a administração socioeconômica está se tornando um diferencial competitivo para as empresas, pois dessa forma é possível traçar estratégias que atendam aos interesses não apenas dos acionistas, mas de todos os stakeholders ${ }^{6}$ que esperam delas atitudes que demonstrem seu engajamento na busca do desenvolvimento sustentável.

\footnotetext{
${ }^{6} \mathrm{O}$ termo inglês stakeholder designa uma pessoa, grupo ou entidade com legítimos interesses nas ações e no desempenho de uma organização e cujas decisões e atuações possam afetar, direta ou indiretamente, essa outra organização. Estão incluídos nos stackeholders os funcionários, gestores, proprietários, fornecedores, clientes, credores, Estado (enquanto entidade fiscal e reguladora), sindicatos e diversas outras pessoas ou entidades que se relacionam com a empresa. Paulo Nunes (Economista, Professor e Consultor de Empresas) 2009.
}

REUNIR - Revista de Administração, Contabilidade e Sustentabilidade - Vol. 1, nº 1, p.52-68, Mai-Ago/2011. 
Para alguns autores, como Ashley (2002), a RSE é uma tendência decorrente da mudança de comportamento dos consumidores, que passaram a se sentir atraídos pelos produtos e práticas que tragam melhoria para a comunidade ou ao meio ambiente. Para Mello Neto e Froes (2001), os empresários que possuem maior discernimento elegeram o social como foco de suas ações empreendedoras, internalizando os conceitos de cidadania empresarial e responsabilidade social e ainda para Peliano (2003), Paoli (2002), foi com o crescente aumento da desigualdade social e a incapacidade do Estado para responder às questões sociais de forma eficiente, que se reforçou o papel das organizações no envolvimento na causa social.

Após estes fatos, surgiram os índices de sustentabilidade empresarial no mercado financeiro. O primeiro deles foi o Sustainability Index, lançado em 1999 pela Dow Jones, empresa americana dedicada a informações sobre negócios. Funciona como uma ferramenta para investidores que buscam empresas que sejam tanto lucrativas, quanto eficientes na integração dos fatores econômicos, ambientais e sociais nas estratégias de seus negócios. No Brasil, a Bolsa de Valores de São Paulo (Bovespa) lançou em 2005 o Índice de Sustentabilidade Empresarial (ISE), que reflete o retorno de uma carteira composta por ações de empresas reconhecidamente comprometidas com a responsabilidade social $\mathrm{e} a$ sustentabilidade empresarial e atua como promotor de boas práticas no meio empresarial brasileiro.

Carroll (1979 apud OLIVEIRA; GOUVÊA; GUAGLIARDI, 2004) destacam as características da RSE:

A responsabilidade social é efetiva quando quatro dimensões de responsabilidade são satisfeitas: econômicas, legais, éticas, e filantrópicas. Assim, cada dimensão é parte de um todo maior, que representa a expectativa da sociedade em relação às empresas.

Com base nesta citação verifica-se a seguir uma pirâmide adaptada envolvendo as quatro dimensões da responsabilidade empresarial, bem como seu grau de importância.

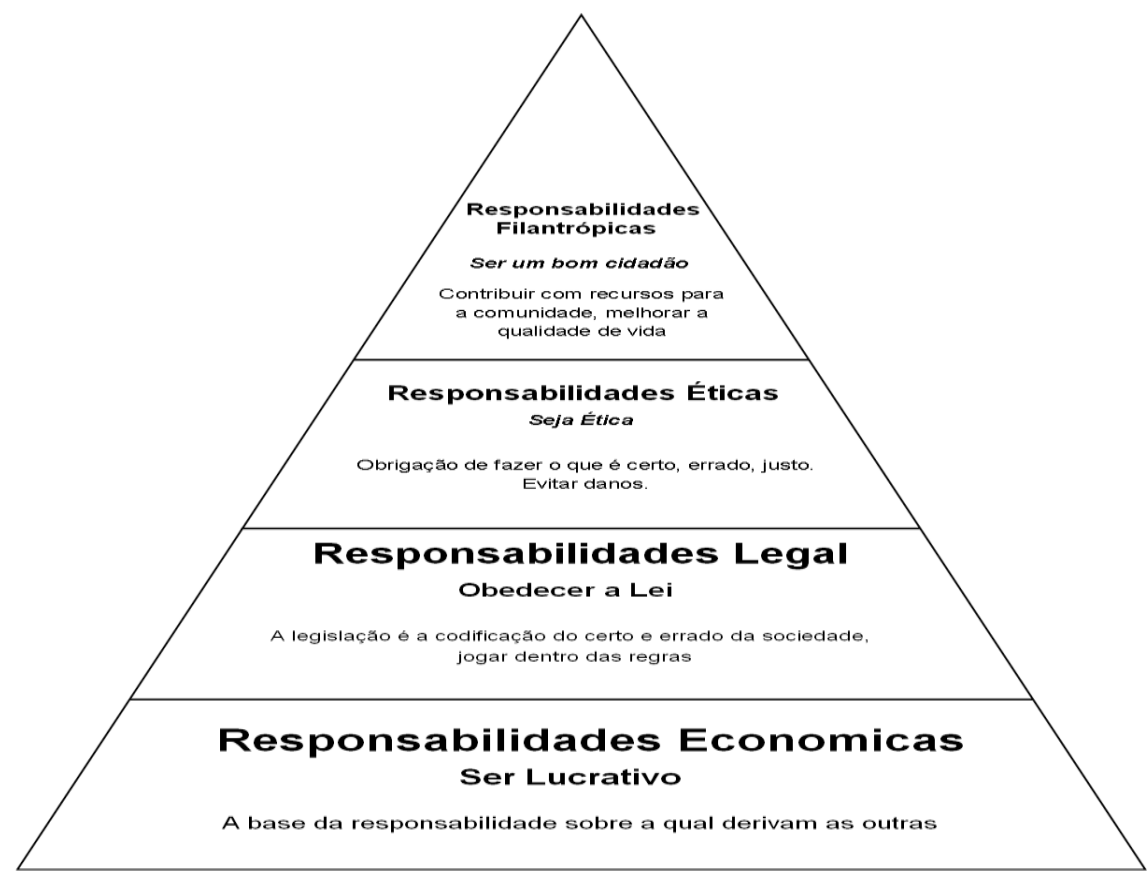

Figura 1 - Pirâmide das Responsabilidades

Fonte: Adaptado de Oliveira, Gouvêa e Guagliardi, 2004, conforme as características da SER.

REUNIR - Revista de Administração, Contabilidade e Sustentabilidade - Vol. 1, nº 1, p.52-68, Mai-Ago/2011. 
Para Freire, Sousa e Ferreira (2008) a Pirâmide das Responsabilidades, de Carroll, se compõe por quatro dimensões: econômica que envolve a lucratividade; legal que diz respeito a obedecer as leis; ética referindo-se a fazer o que é certo; evitar causar danos; e discricionária envolvendo ser um bom cidadão, contribuir para a comunidade e qualidade de vida.

De acordo com Fischer (2002), Ashley (2002), embora haja grande diversidade das atuações das empresas no que tange à responsabilidade social, é possível identificar dois tipos básicos: o primeiro considera as ações sociais como bens geradores de resultados para a população-alvo; o segundo considera essas ações em termos estratégicos de negócio, objetivando a melhoria do desempenho do produto e da marca.

Mello Neto e Froes (2001) possuem opinião similar ao afirmarem que as empresas desenvolvem projetos sociais com objetivos de filantropia empresarial e de marketing.

Segundo o Instituto ETHOS (2010) em sua publicação eletrônica:

Responsabilidade social empresarial é a forma de gestão que se define pela relação ética e transparente da empresa com todos os públicos com os quais ela se relaciona e pelo estabelecimento de metas empresariais que impulsionem o desenvolvimento sustentável da sociedade, preservando recursos ambientais e culturais para as gerações futuras, respeitando a diversidade e promovendo a redução das desigualdades sociais.

\subsection{Investimento Social Privado (ISP)}

Para Agnelli (2010), Investimento Social Privado (ISP) é um repasse voluntário de recursos privados de forma planejada, na qual se mantém um controle, desde que esta seja sistemática, ou seja, contínua, para projetos sociais, ambientais e culturais de interesse público.

O investimento social privado não pode ser confundido com caridade, pois nesta apenas se transfere valores às entidades interessadas e o processo se encerra, quando há um investimento social privado os investidores interessam-se pelos resultados obtidos, há, portanto, a preocupação em se gerar um retorno positivo à sociedade e à empresa, de forma que o monitoramento das atividades desempenhadas seja constante e envolva uma equipe de profissionais especializados e empenhados com as causas sociais em questão.

Ainda de acordo com Agnelli (2010), um novo conceito de investimento social, diz que nasce uma nova lógica de ISP em que o papel da empresa sai da aplicação de recursos em projetos sociais e segue para a associação com o governo e a sociedade civil organizada. A idéia é que todos trabalhem juntos para estimular vocações locais e solucionar problemas através de ações fundamentais, essa nova concepção tem uma lógica incontestável, melhor do que trabalhar sozinho em prol de um bem comum é se aliar a todos os interessados para trabalhar em conjunto.

Segundo Fischer et. al. (2005, apud MILANI FILHO, 2008, p. 4):

No Brasil, o ISP é materializado em projetos sociais desenvolvidos a partir de parcerias ou alianças entre o Segundo e o Terceiro Setor. Sob essa perspectiva, as empresas direcionam recursos para organizações não-governamentais sem fins lucrativos para a promoção de determinada ação social.

A opinião de Fischer et. al. (2005, apud MILANI FILHO, 2008) apesar de não ser exatamente igual a do Instituto Ethos, segue a mesma linha de pensamento e isso é uma

REUNIR - Revista de Administração, Contabilidade e Sustentabilidade - Vol. 1, nº 1, p.52-68, Mai-Ago/2011. 
constante não só neste meio, mas na sociedade em geral e algo é certo para essas empresas, a organização tradicional, com a esfera apenas econômica, que visa apenas o lucro, sem considerar os aspectos sociais está sendo questionada pela sociedade (MEDEIROS, 2006).

\section{PROCEDIMENTOS METODOLÓGICOS}

Para a realização do presente estudo foi realizado uma pesquisa bibliográfica e documental. Neste caso os documentos utilizados foram as Demonstrações do Resultado de Exercício (DRE) de 2002 a 2009 das empresas listadas no ISE e os índices do ISE no período de 2005 a 2009.

Com o intuito de proporcionar respaldo confiável ao estudo, optou-se por escolher empresas listadas na BMF\&BOVESPA, no total foram 320 empresas listadas e como o presente trabalho irá enfocar apenas as empresas socialmente responsáveis então o foco serão as empresas que compõem o ISE, por sua vez os critérios adotados para a escolha destas empresas abrangem as dimensões ambiental, social e econômico-financeira, o qual subdividisse em quatro conjuntos de critérios: Políticas (indicadores de comprometimento); Gestão (indicadores de programas, metas e monitoramento); Desempenho e Cumprimento legal. Nessa pesquisa o procedimento adotado foi o de comparar o lucro ou prejuízo acumulado encontrado nas demonstrações do resultado do exercício das empresas que compõe esse índice com o valor de mercado do mesmo, com o intuito de verificar a sua proporção em relação ao faturamento. Utilizando uma amostra de 28 (vinte e oito) empresas dos mais variados setores para facilitar a análise comparativa e evitar possíveis distorções nos resultados, ressalte-se que o rol de empresas escolhidas deve-se ao fato de serem as que fizeram parte do ISE no período estudado que compreende os anos de 2005 a 2009.

As empresas foco da pesquisa são representantes de 12 (Doze) setores diferentes. São eles: Energia; Saúde; Intermediários Financeiros; Químicos; Produtos de Uso Pessoal e de Limpeza; Material de Transporte; Madeira e Papel; Alimentos; Siderurgia e Metalúrgica; Água e Saneamento; Telefonia Fixa e Telefonia Móvel.

Contudo, observando a questão da comparação do resultado dessas empresas com valor de mercado do ISE, utilizou-se os períodos que as empresas faziam parte desse índice. Como a primeira carteira do ISE foi divulgada em 30 de novembro de 2005, entrando em vigor um dia depois, ou seja, dia 01 de dezembro de 2005, nesse ano este índice vigorou apenas um mês, portanto, o período para essa pesquisa tem início em 2006.

Nesse sentido, optou-se por trabalhar em um período igual antes e depois do ingresso no ISE, 04 anos antes e 04 anos depois, visando obter uma amplitude que tivesse uma mesma margem de observação. Após a coleta dos resultados líquidos das empresas e dos valores do ISE, utilizou-se da planilha Excel 2007 - Microsoft Office 2007 para o agrupamento dos dados.

Para verificar o comportamento dos resultados das empresas utilizou-se da ferramenta de gráfico de linhas, já para verificar a relação entre os resultados e o valor de mercado da ISE utilizou-se da análise de regressão e correlação. Quanto a essa análise de regressão e correlação, o método utilizado foi a Regressão Simples, não linear, mas antes de adentrar no assunto é preciso entender sobre as regressões lineares neste caso, Mazucheli e Achcar (2002) comentam que depois de observar um conjunto de dados, identifica-se o modelo que melhor explique a relação entre eles. Sobre o caso não-linear, observa-se que para os mesmos autores na maioria das vezes, as formulações de possíveis modelos são baseadas em considerações teóricas inseparáveis ao fenômeno que se tem interesse no modelo.

REUNIR - Revista de Administração, Contabilidade e Sustentabilidade - Vol. 1, nº 1, p.52-68, Mai-Ago/2011. 
A análise gráfica bem como a de regressão serão realizadas conforme detalhamento a seguir: estipulação das variáveis através de pesquisas documentais, das quais foram determinadas as variáveis independentes (ISE nos valores referentes aos anos de 2006 a 2009) e variáveis dependentes (Lucro das empresas que compõem ou compuseram a carteira de ações do ISE desde a sua criação - referentes aos anos de 2002 a 2009).

Essas técnicas permitirão explicar, a correlação existente entre os valores das variáveis estudadas, uma em função da outra, podendo-se verificar uma relação de causa e efeito entre as variáveis. Para fins de esclarecimento usa-se correlação entre duas ou mais variáveis quando as alterações sofridas por uma delas são acompanhadas por modificações nas outras.

Nesta pesquisa, os documentos objeto de análise serão a DRE e o ISE. Os documentos serão acessados via internet, através dos sítios das empresas em estudo e da Bolsa de Valores do Estado de São Paulo.

A coleta das informações foi realizada a partir da Demonstração do Resultado do Exercício de cada empresa, a fonte proveniente destas informações foi o site da BM\&FBOVESPA, o foco da questão na DRE foi o "Lucro/Prejuízo do Período" que mostra qual foi a receita ou despesa da empresa, neste caso, durante os anos de 2002, 2003, 2004, 2005, 2006, 2007, 2008 e 2009, (quatro anos antes da criação do ISE e quatro anos depois da criação do ISE).

\section{APRESENTAÇÃO E DISCUSSÃO DOS RESULTADOS}

Os resultados líquidos das 28 (vinte e oito) empresas objetos da presente investigação podem ser visualizados na tabela seguinte.

Observa-se na tabela 1 que inexiste resultado das empresas DASA (2002), EMBRAER e DURATEX (2002 e 2003) pelo fato de, nesses anos, não haver divulgação das demonstrações no site da BOVESPA.

A evolução do lucro das empresas pode ser visualizado nas tabelas 1 e 2 durante o período analisado (2002 a 2009), bem como no gráfico 1.

Tabela 1 - Lucro na DRE nos 04 (quatro) anos anteriores ao ingresso no ISE

\begin{tabular}{lrrrr}
\hline \multirow{2}{*}{ EMPRESAS } & \multicolumn{3}{c}{ LUCRO NA DRE ANTES DO ISE } \\
\cline { 2 - 5 } & $\mathbf{2 0 0 2}$ & $\mathbf{2 0 0 3}$ & $\mathbf{2 0 0 4}$ & $\mathbf{2 0 0 5}$ \\
\hline CPFL ENERGIA & -696063 & -297392 & 278919 & $\mathrm{R} \$ 1.021 .278$ \\
\hline ELETROPAULO & -871079 & 86275 & 5635 & $-\mathrm{R} \$ 155.533$ \\
\hline TRACTEBEL & -183521 & 517154 & 775192 & $\mathrm{R} \$ 920.096$ \\
\hline CEMIG & -1001833 & 1197642 & 1384801 & $\mathrm{R} \$ 2.003 .399$ \\
\hline DASA & Fora da Bovespa & -8482 & -18859 & $\mathrm{R} \$ 10.157$ \\
\hline BRADESCO & 2022588 & 2306339 & 3060151 & $\mathrm{R} \$ 5.514 .074$ \\
\hline BANCO DO BRASIL & 2027676 & 2380982 & 3024006 & $\mathrm{R} \$ 610.151$ \\
\hline SUZANO PAPEL \& CELULOSE & 55078 & 586518 & 602959 & $\mathrm{R} \$ 499.649$ \\
\hline BRASKEM & -957675 & 215135 & 690857 & $\mathrm{R} \$ 625.837$ \\
\hline NATURA & 21741 & 63884 & 300294 & $\mathrm{R} \$ 396.881$ \\
\hline EMBRAER & Fora da Bovespa & Fora da Bovespa & 1280866 & $\mathrm{R} \$ 708.935$ \\
\hline ITAUUNIBANCO & 2376723 & 3151820 & 3775616 & $\mathrm{R} \$ 5.251 .334$ \\
\hline BRF FOODS Perdigão & 8232 & 123547 & 295619 & $\mathrm{R} \$ 360.964$ \\
\hline
\end{tabular}

REUNIR - Revista de Administração, Contabilidade e Sustentabilidade - Vol. 1, nº 1, p.52-68, Mai-Ago/2011. 


\begin{tabular}{lrrrr}
\hline FIBRIA & 282882 & 852937 & 789677 & $\mathrm{R} \$ 549.131$ \\
\hline AES TIETE & -2522 & 195371 & 291512 & $\mathrm{R} \$ 556.052$ \\
\hline CESP & -3417524 & 627680 & 34059 & $-\mathrm{R} \$ 195.761$ \\
\hline COELCE & 83342 & 91440 & 36529 & $\mathrm{R} \$ 189.124$ \\
\hline COPEL & -320019 & 171137 & 374148 & $\mathrm{R} \$ 1.078 .744$ \\
\hline DURATEX & Fora da Bovespa & Fora da Bovespa & 17110 & $\mathrm{R} \$ 23.322$ \\
\hline ELETROBRAS & 1100340 & 323125 & 1293314 & $\mathrm{R} \$ 974.589$ \\
\hline ENERGIAS BR & -4377 & -189521 & 106875 & $\mathrm{R} \$ 439.406$ \\
\hline GERDAU & 798688 & 1137216 & 2831339 & $\mathrm{R} \$ 2.781 .340$ \\
\hline GERDAU MET & 434028 & 575179 & 1437075 & $\mathrm{R} \$ 1.275 .584$ \\
\hline ITAUSA & 1537264 & 1561263 & 1962392 & $\mathrm{R} \$ 2.297 .173$ \\
\hline LIGHT S/A & -1255576 & -488403 & -97606 & $\mathrm{R} \$ 242.844$ \\
\hline SABESP & -650516 & 833320 & 513028 & $\mathrm{R} \$ 865.647$ \\
\hline TELEMAR & -415598 & 212713 & 751037 & $\mathrm{R} \$ 1.114 .113$ \\
\hline TIM PART S/A & 65774 & 120802 & 265935 & $\mathrm{R} \$ 389.574$ \\
\hline Valor Total & $\mathbf{1 0 3 8 0 5 3}$ & $\mathbf{1 6 3 4 7 6 8 1}$ & $\mathbf{2 6 0 6 2 4 8 0}$ & $\mathbf{3 0 3 4 8 1 0 4}$ \\
\hline Fo: BM\& & & & &
\end{tabular}

Fonte: BM\&FBOVESPA, 2010.

Tabela 2 - Lucro na DRE nos 04 (quatro) anos posteriores ao ingresso no ISE

\begin{tabular}{lrrrr}
\hline \multirow{2}{*}{ EMPRESAS } & \multicolumn{4}{c}{ LUCRO NA DRE DEPOIS DO ISE } \\
\cline { 2 - 6 } CPFL ENERGIA & $\mathbf{2 0 0 6}$ & \multicolumn{1}{c}{$\mathbf{2 0 0 7}$} & \multicolumn{1}{c}{$\mathbf{2 0 0 8}$} & \multicolumn{1}{c}{ 2009 } \\
\hline ELETROPAULO & $\mathrm{R} 1.404 .096$ & $\mathrm{R} \$ 1.640 .727$ & $\mathrm{R} \$ 1.275 .692$ & $\mathrm{R} \$ 1.286 .470$ \\
\hline TRACTEBEL & $\mathrm{R} \$ 973.371$ & $\mathrm{R} \$ 712.631$ & $\mathrm{R} \$ 1.027 .109$ & $\mathrm{R} \$ 1.063 .194$ \\
\hline CEMIG & $\mathrm{R} \$ 1.718 .841$ & $\mathrm{R} \$ 1.745 .311$ & $\mathrm{R} \$ 1.887 .035$ & $\mathrm{R} \$ 1.861 .403$ \\
\hline DASA & $\mathrm{R} \$ 16.511$ & $\mathrm{R} \$ 56.621$ & $-\mathrm{R} \$ 12.980$ & $\mathrm{R} \$ 83.814$ \\
\hline BRADESCO & $\mathrm{R} \$ 5.054 .040$ & $\mathrm{R} \$ 8.009 .724$ & $\mathrm{R} \$ 7.620 .238$ & $\mathrm{R} \$ 8.012 .282$ \\
\hline BANCO DO BRASIL & $\mathrm{R} \$ 681.493$ & $\mathrm{R} \$ 5.058 .119$ & $\mathrm{R} \$ 8.802 .869$ & $\mathrm{R} \$ 10.147 .522$ \\
\hline SUZANO PAPEL \& CELULOSE & $\mathrm{R} \$ 443.690$ & $\mathrm{R} \$ 536.601$ & $-\mathrm{R} \$ 451.308$ & $\mathrm{R} \$ 877.932$ \\
\hline BRASKEM & $\mathrm{R} \$ 101.349$ & $\mathrm{R} \$ 621.802$ & $-\mathrm{R} \$ 2.492 .107$ & $\mathrm{R} \$ 917.228$ \\
\hline NATURA & $\mathrm{R} \$ 460.773$ & $\mathrm{R} \$ 465.409$ & $\mathrm{R} \$ 517.857$ & $\mathrm{R} \$ 683.924$ \\
\hline EMBRAER & $\mathrm{R} \$ 621.727$ & $\mathrm{R} \$ 1.185 .179$ & $\mathrm{R} \$ 428.750$ & $\mathrm{R} \$ 894.590$ \\
\hline ITAUUNIBANCO & $\mathrm{R} \$ 4.308 .927$ & $\mathrm{R} \$ 8.473 .604$ & $\mathrm{R} \$ 7.803 .483$ & $\mathrm{R} \$ 10.066 .608$ \\
\hline BRF FOODS Perdigão & $\mathrm{R} \$ 117.253$ & $\mathrm{R} \$ 321.307$ & $\mathrm{R} \$ 54.372$ & $\mathrm{R} \$ 120.427$ \\
\hline FIBRIA & $\mathrm{R} \$ 655.842$ & $\mathrm{R} \$ 836.878$ & $-\mathrm{R} \$ 1.310 .347$ & $\mathrm{R} \$ 558.051$ \\
\hline AES TIETE & $\mathrm{R} \$ 614.127$ & $\mathrm{R} \$ 609.110$ & $\mathrm{R} \$ 692.462$ & $\mathrm{R} \$ 780.235$ \\
\hline CESP & $-\mathrm{R} \$ 118.365$ & $\mathrm{R} \$ 178.591$ & $-\mathrm{R} \$ 2.351 .639$ & $\mathrm{R} \$ 762.713$ \\
\hline COELCE & $\mathrm{R} \$ 298.258$ & $\mathrm{R} \$ 244.751$ & $\mathrm{R} \$ 338.523$ & $\mathrm{R} \$ 334.448$ \\
\hline COPEL & $\mathrm{R} \$ 1.026 .433$ & $\mathrm{R} \$ 1.106 .610$ & $\mathrm{R} \$ 1.078 .744$ & $\mathrm{R} \$ 1.026 .433$ \\
\hline DURATEX & $-\mathrm{R} \$ 2.215$ & $\mathrm{R} \$ 46.693$ & $\mathrm{R} \$ 75.095$ & $\mathrm{R} \$ 97.935$ \\
\hline ELETROBRAS & $\mathrm{R} \$ 1.161 .318$ & $\mathrm{R} \$ 1.547 .857$ & $\mathrm{R} \$ 6.136 .497$ & $\mathrm{R} \$ 170.526$ \\
\hline ENERGIAS BR & $\mathrm{R} \$ 394.120$ & $\mathrm{R} \$ 450.444$ & $\mathrm{R} \$ 388.779$ & $\mathrm{R} \$ 625.137$ \\
\hline & & & &
\end{tabular}

REUNIR - Revista de Administração, Contabilidade e Sustentabilidade - Vol. 1, nº 1, p.52-68, Mai-Ago/2011. 


\begin{tabular}{lrrrr}
\hline GERDAU & $\mathrm{R} \$ 2.880 .922$ & $\mathrm{R} \$ 3.042 .131$ & $\mathrm{R} \$ 2.881 .243$ & $\mathrm{R} \$ 1.122 .860$ \\
\hline GERDAU MET & $\mathrm{R} \$ 1.345 .474$ & $\mathrm{R} \$ 1.435 .058$ & $\mathrm{R} \$ 1.241 .649$ & $\mathrm{R} \$ 492.065$ \\
\hline ITAUSA & $\mathrm{R} \$ 4.485 .631$ & $\mathrm{R} \$ 3.988 .482$ & $\mathrm{R} \$ 2.699 .680$ & $\mathrm{R} \$ 3.930 .204$ \\
\hline LIGHT S/A & $\mathrm{R} \$ 210.323$ & $\mathrm{R} \$ 1.074 .330$ & $\mathrm{R} \$ 974.453$ & $\mathrm{R} \$ 604.831$ \\
\hline SABESP & $\mathrm{R} \$ 778.905$ & $\mathrm{R} \$ 1.055 .264$ & $\mathrm{R} \$ 63.571$ & $\mathrm{R} \$ 1.373 .879$ \\
\hline TELEMAR & $\mathrm{R} \$ 1.309 .955$ & $\mathrm{R} \$ 2.317 .820$ & $\mathrm{R} \$ 1.154 .280$ & $-\mathrm{R} \$ 435.962$ \\
\hline TIM PART S/A & $-\mathrm{R} \$ 301.683$ & $\mathrm{R} \$ 68.302$ & $\mathrm{R} \$ 180.152$ & $\mathrm{R} \$ 214.893$ \\
\hline Valor Total & $\mathbf{R} \mathbf{3 0 5 9 9 6 1 6}$ & $\mathbf{R} \mathbf{4 7 8 7 4 9 8 3}$ & $\mathbf{R} \mathbf{4 1 8 1 9 3 0 5}$ & $\mathbf{R} \mathbf{4 8 8 0 8 0 4 0}$ \\
\hline ISE & $\mathbf{R} \mathbf{4} \mathbf{1 . 4 3 3 , 4 2}$ & $\mathbf{R} \mathbf{2 . 0 1 1 , 8 1}$ & $\mathbf{R} \mathbf{1 . 1 8 5 , 1 9}$ & $\mathbf{R} \mathbf{1 . 9 7 2 , 0 4}$ \\
\hline
\end{tabular}

Fonte: BM\&FBOVESPA, 2010.

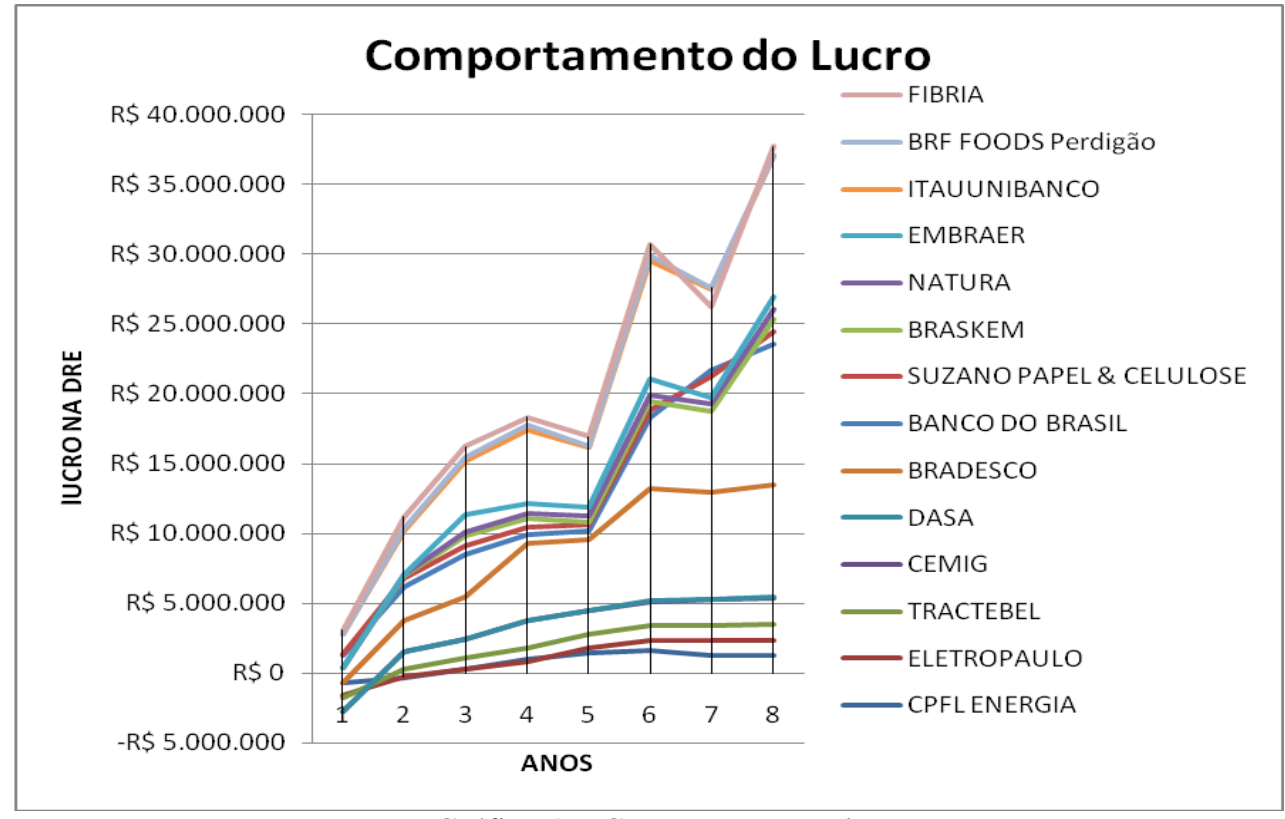

Gráfico 1 - Comportamento do Lucro

Fonte: Dados da pesquisa, 2010.

Percebe-se que, os resultados das empresas apresentaram um crescimento no decorrer dos 8 anos e que esse mostra-se mais evidente a partir do ano de 2007, um ano após o ingresso na carteira ISE, o que confirma as expectativas da BOVESPA.

Tal comportamento pode ser mais bem visualizado ao avaliar o resultado conjunto da carteira (vide gráfico 3).

REUNIR - Revista de Administração, Contabilidade e Sustentabilidade - Vol. 1, nº 1, p.52-68, Mai-Ago/2011. 


\section{Evolução do Lucro no Período Estudado}

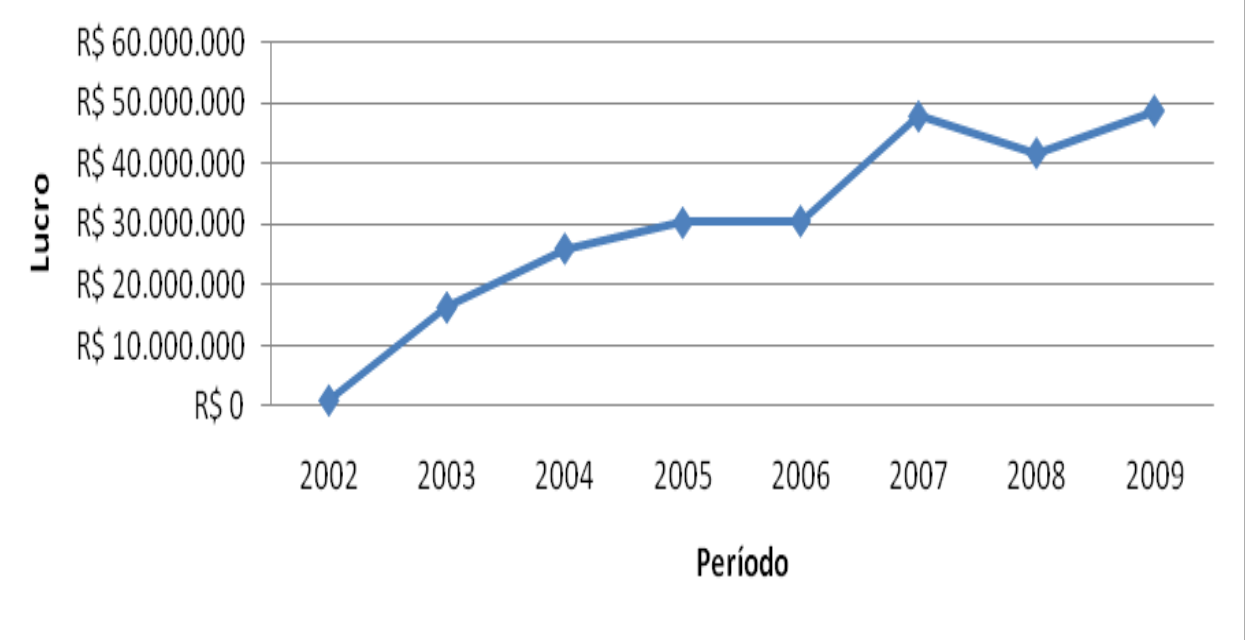

Gráfico 2 - Evolução do Lucro no Período Estudado

Fonte: Dados da pesquisa, 2010.

O gráfico 2 confirma a ideia de que as empresas vinham apresentando uma valorização crescente em suas ações e que no ano de 2007 houve um grande salto, ou seja, um ano após o ingresso na carteira ISE e que, mesmo com uma queda no ano seguinte, ainda apresentou resultados bem superiores aqueles obtidos anteriores a 2006, voltando a crescer no ano de 2009.

No momento em que as 28 empresas socialmente responsáveis passam a integrar a carteira do ISE (2005 a 2006) seus resultados continuam positivo, no entanto foram menores do que no ano anterior (2004), mais precisamente, $15,61 \%$ abaixo do que se realizou no ano anterior, provavelmente justificado pela configuração econômica excêntrica no mercado nesta época e concomitantemente ao fato de o índice ser novo no mercado e portanto, passível de desconhecimento por parte dos potenciais investidores financeiros.

No segundo ano de vigência do ISE (2007) os resultados financeiros destas empresas já apresentam a maior alta desde o ingresso no ISE, com um aumento de 56,46\% de alta em seus lucros, uma alta considerável, uma vez que, por exemplo, o Índice BOVESPA IBOVESPA, que é referência em indicar/retratar o comportamento/desempenho médio das cotações do mercado de ações brasileiro dos principais papéis negociados na BM\&FBOVESPA no mesmo ano em relação ao ano anterior aumentou 43,65\%.

Em meados de 2007 devido à crise financeira ocorrida no mundo pelo estouro da bolha imobiliária criada nos Estados Unidos, muitos investidores buscaram proteger seus investimentos e muitas vezes a alternativa usada foi a venda de papéis acionários de maneira exorbitada, causando assim uma queda drástica nas ações de inúmeras empresas, incluindo-se neste rol as empresas participantes do ISE, justificando-se assim o prejuízo realizado neste ano de $-12,65 \%$ abaixo do realizado no ano anterior, ainda sim se comparado com o Índice Bovespa sua queda foi muito baixa, pois o Índice Bovespa neste ano fechou com baixa de $41,22 \%$.

Um ano depois da crise financeira, aquelas empresas que possuíam um respaldo de confiança no mercado, voltaram a crescer rapidamente, e o ISE ajudou de forma imprescindível na recuperação das empresas que faziam parte dela, essas empresas

REUNIR - Revista de Administração, Contabilidade e Sustentabilidade - Vol. 1, nº 1, p.52-68, Mai-Ago/2011. 
reconhecidas como socialmente responsáveis passaram a vender seus papéis acima da média àqueles investidores que buscavam segurança em seus investimentos e assim houve uma alta em sua lucratividade de $16,71 \%$

O gráfico 3, mostra o comportamento do ISE desde o ano de 2005.

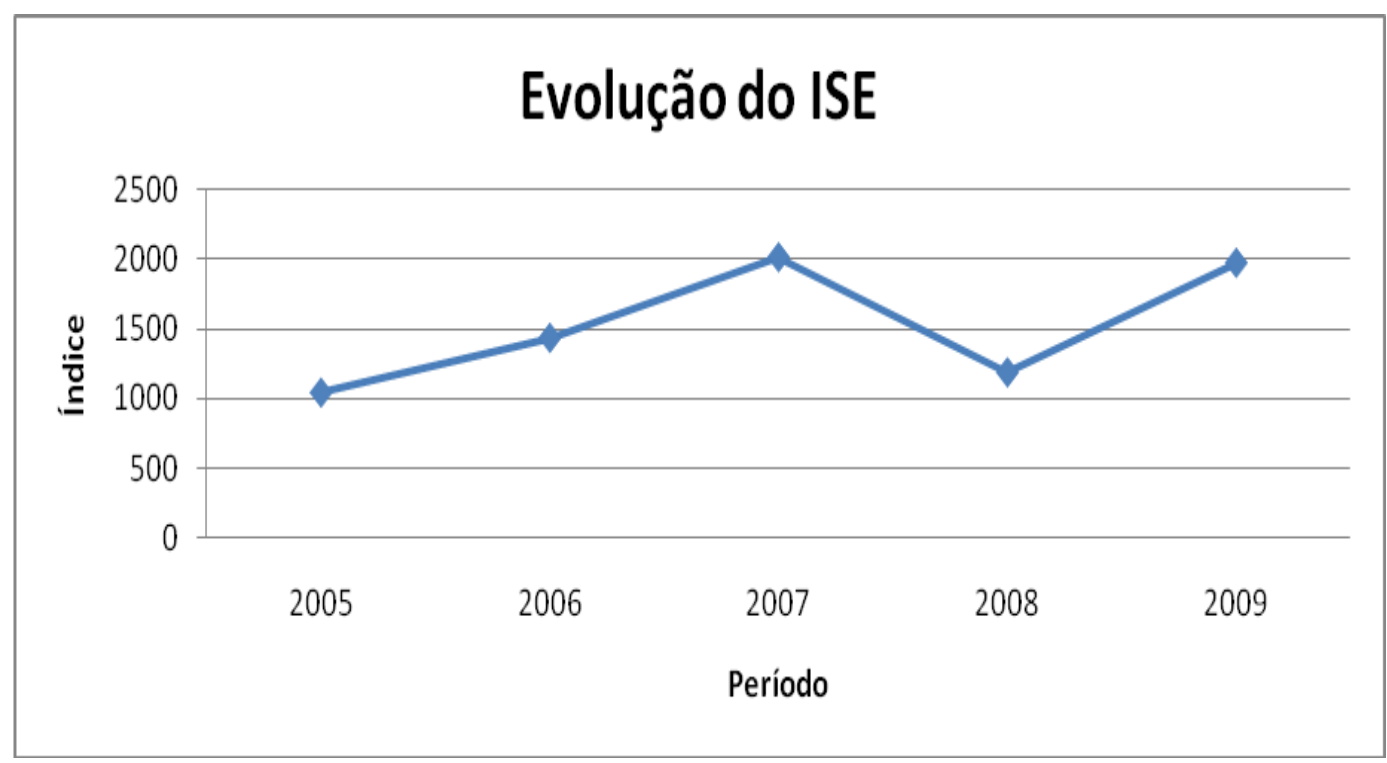

Gráfico 3 - Evolução do ISE

Fonte: Dados da pesquisa, 2010.

A Tabela 2 mostra a variação em percentuais evidenciando a alta nos dois primeiros anos completos de fechamento, tendo uma baixa no terceiro ano e posteriormente uma alta no fechamento de 2009.

Tabela 2 - Evolução do ISE

\begin{tabular}{c|c}
\hline \hline ANO DE FECHAMENTO & \% \\
\hline 2006 & $+37,82$ \\
\hline 2007 & $+40,35$ \\
\hline 2008 & $-41,09$ \\
\hline 2009 & $+66,39$ \\
\hline \multicolumn{2}{c}{ Fonte: Dados da pesquisa, 2010. }
\end{tabular}

No que se refere ao gráfico 4, observa-se ainda que o ISE apresenta um comportamento semelhante ao observado no resultado das empresas. Quando se sobrepõe a evolução do lucro no período estudado, apenas os anos de 2005 a 2009 (gráfico 4) à evolução do ISE (gráfico 5) fica mais visível a correlação entre as duas variáveis, como pode ser observado no Gráfico 6. 


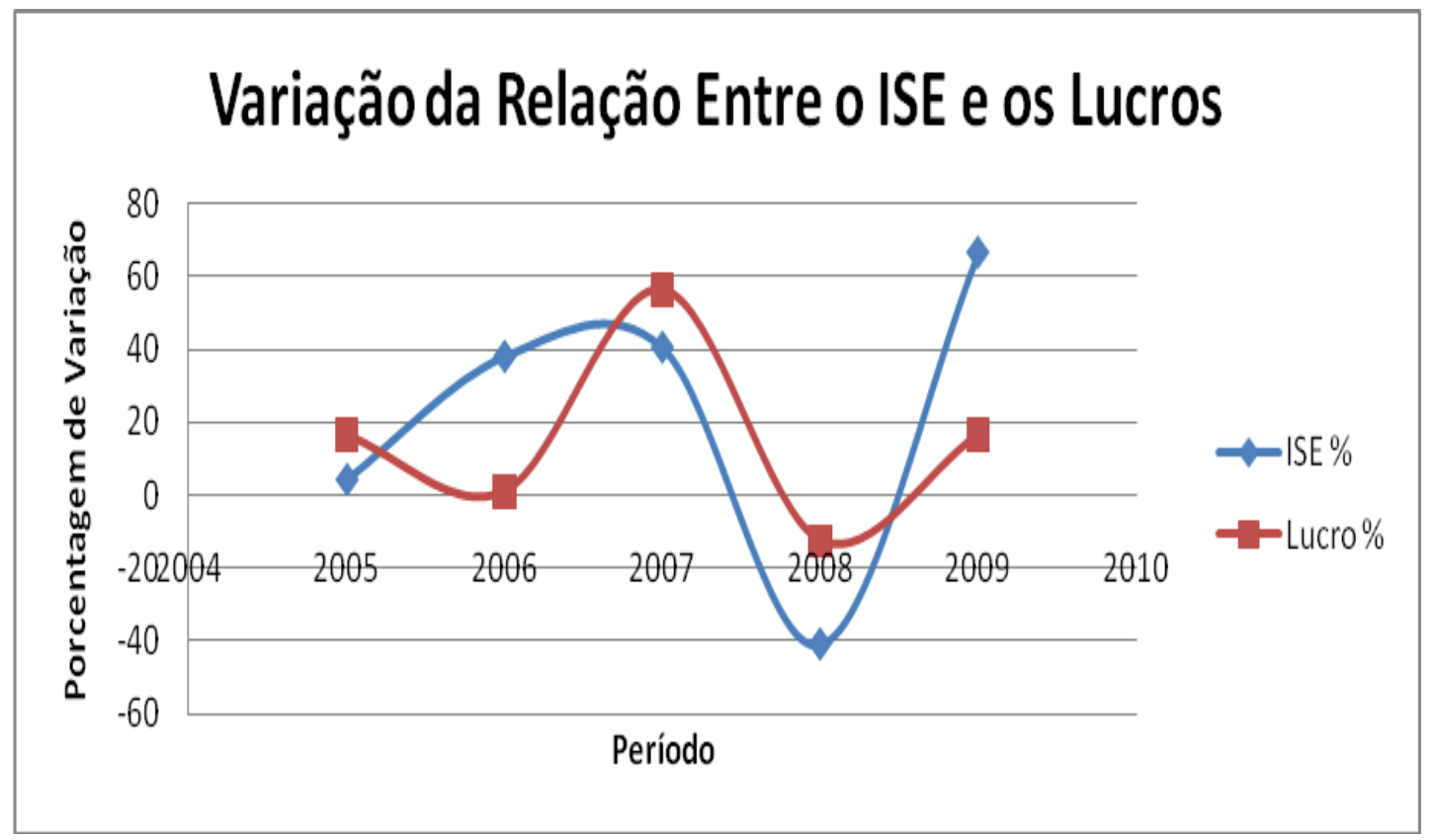

Gráfico 4 - Variação da Relação Entre o ISE e os Lucros.

Fonte: Dados da pesquisa, 2010.

No entanto, para confirmar que o valor do ISE possui alguma relação, que possa ser explicada, com os resultados das empresas que a compõe, evitando que tal fato seja considerado uma eventualidade e que possa ser explicado cientificamente, procedeu-se a análise de correlação e regressão não linear, obtendo-se o coeficiente de determinação, como pode ser visualizado no gráfico 5.

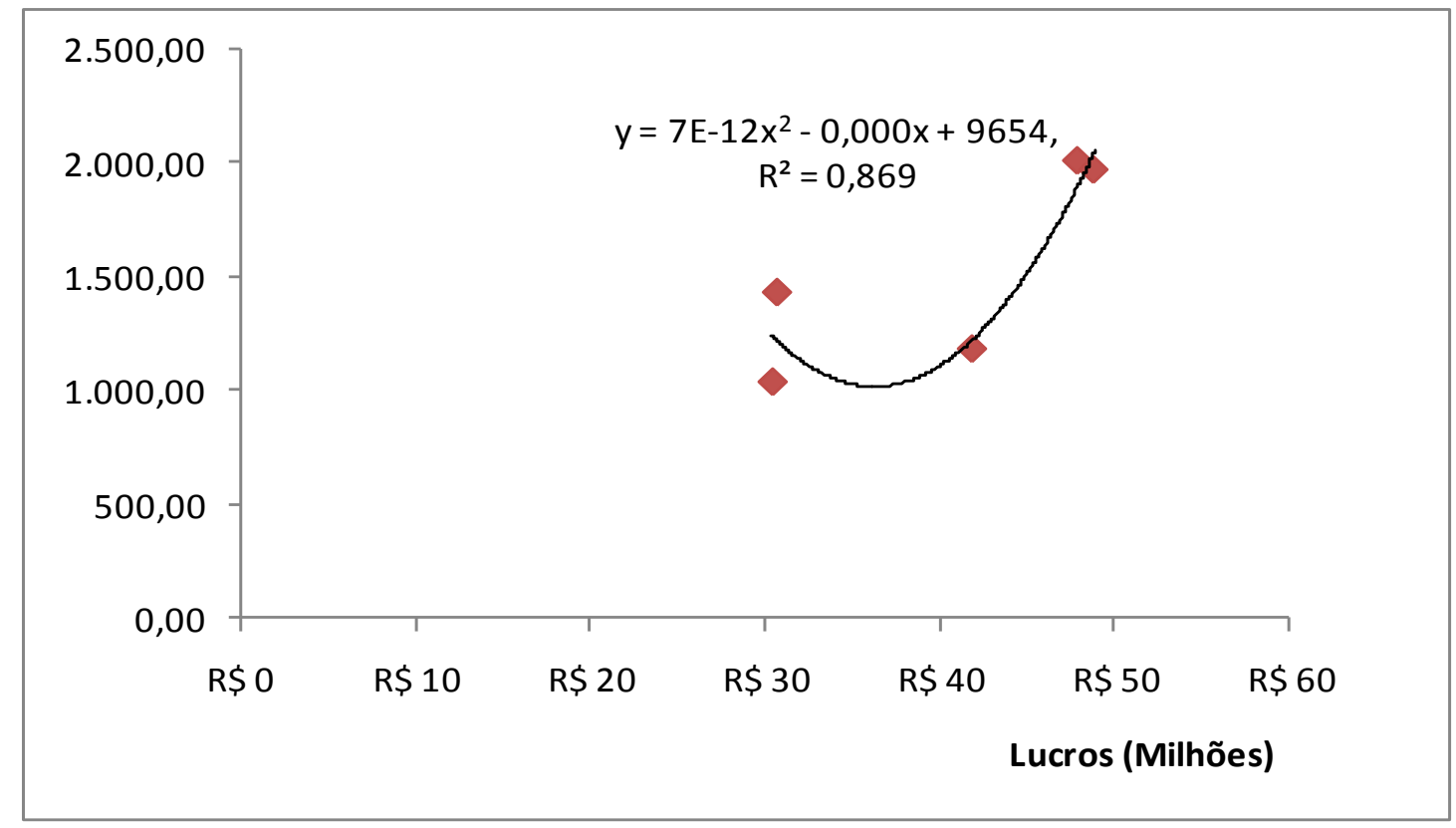

Gráfico 5 - Gráfico de Dispersão

Fonte: Dados da Pesquisa, 2010.

REUNIR - Revista de Administração, Contabilidade e Sustentabilidade - Vol. 1, nº 1, p.52-68, Mai-Ago/2011. 
A regressão não linear - Quadrática, proporcionou um coeficiente de determinação $\left(\mathrm{R}^{2}\right)$ de 0,869 , ou seja, $86,9 \%$ das variações do ISE são explicadas pela variação nos resultados da carteira.

\section{CONSIDERAÇÕES FINAIS}

Após a realização da pesquisa documental e bibliográfica, bem como as análises dos dados obtidos, torna-se possível responder se os resultados líquidos das empresas integrantes do ISE possuem algum relacionamento com o valor dessa carteira, questão essa declarada anteriormente como a problemática da pesquisa.

Sendo o objetivo geral responder a esta pergunta, e uma vez definido os caminhos para se chegar a uma resposta, através da coleta do resultado líquido das empresas listadas no ISE no período de 2002 a 2009 e da coleta dos valores da carteira do ISE no período de 2005 a 2009, tornou-se possível chegar a seguinte conclusão:

As duas variáveis apresentam relação entre si:

1. Valores da carteira do ISE no período de 2005 a 2009; Variável Independente.

2. Receita Líquida das empresas listadas no ISE no período de 2002 a 2009; Variável Dependente.

E a relação entre elas é de 0,869 , segundo Peternelli (2010) na análise de regressão simples, quanto mais perto de "1" esse índice estiver, maior sua correlação entre as duas variáveis, portanto é possível afirmar que, quanto mais cresce a variável independente - ISE também mais crescerá a variável dependente - os lucros das empresas que compõem esse índice.

Em termos percentuais, conclui-se que $86,9 \%$ das variações do ISE são explicadas pela variação nos resultados da carteira e pode ser determinada pela equação.

Com esse resultado obtido através da análise de Regressão e Correlação Simples não Linear, evidencia-se que nos anos em que as empresas passaram a fazer parte da composição da carteira do ISE, suas receitas líquidas passaram a variar concomitantemente, ou seja, simultaneamente e proporcionalmente a variação do ISE.

Devido ao curto espaço de tempo disponível para a elaboração desta pesquisa e a algumas limitações técnicas quanto a coleta de dados é possível que haja alguma variação nos resultados obtidos, principalmente quanto a coleta documental, devido a exclusão do primeiro mês em que o ISE vigorou (dezembro de 2005) e aos primeiros meses de 2010, que também ficaram fora da análise, isso não significa que os resultados auferidos estejam inconsistentes, pelo contrário, isso significa dizer que a utilização dos dados exclusos poderão demonstrar um resultado mais preciso e exato.

A sugestão que remeto é que aos interessados por uma pesquisa mais precisa utilizem os dados sempre atualizados processando-os nas mesmas técnicas aqui utilizadas, uma vez que o mercado financeiro trata-se de um mercado muito volátil e os resultados aqui obtidos no período estudado não serão mais os mesmos em outro período.

\section{REFERÊNCIAS}

REUNIR - Revista de Administração, Contabilidade e Sustentabilidade - Vol. 1, nº 1, p.52-68, Mai-Ago/2011. 
AGNELLI, Roger. Uma nova lógica de investimento social. Disponível em: http://site.gife.org.br/artigos_reportagens_conteudo12951.asp. Acesso em 29 mar. 2010. Link

ALVES, M. A. Terceiro Setor: O dialogismo Polêmico. 2002. (Relatório de pesquisa). FGV Fundação Getúlio Vargas Escola de Administração de Empresas de São Paulo, São Paulo, 2002. Disponível em: http://hdl.handle.net/10438/4455. Acesso em: 05 abr. 2010. Link

ASHLEY, Patrícia A. (coord.). Ética e responsabilidade social nos negócios. São Paulo: Saraiva, 2002.

BMF\&BOVESPA. Índice de Sustentabilidade Empresarial. Disponível em: http://www.bmfbovespa.com.br/indices/ResumoIndice.aspx? Indice=ISE\&Idioma=pt-BR.

Acesso em 09 jun. 2010. Link

CFC - Conselho Federal de Contabilidade. Apêndice Resolução Sobre os Princípios Fundamentais de Contabilidade. A CONTABILIDADE COMO CIÊNCIA SOCIAL Disponível em: http://www.cfc.org.br/sisweb/sre/detalhes_sre.aspx?Codigo=1994/000774. Acesso em 14 mar. 2010. Link

FERNANDES, Carlos. Herbert José de Sousa. O Betinho. Universidade Federal de Campina Grande. Disponível em: http://www.dec.ufcg.edu.br/biografias/HerbJSou.html. Acesso em 26 mai. 2010. Link

FISCHER, Rosa M. O desafio da colaboração: práticas de responsabilidade social entre empresas e terceiro setor. São Paulo: Gente, 2002.

FREIRE, Robson; SOUSA, Maria José Barbosa de; FERREIRA, Elaine. Responsabilidade social corporativa: evolução histórica dos modelos internacionais. 2008. Disponível em: http://www.aedb.br/seget/artigos08/257_257_RSC_-_evolucao_historica_dos_modelos.pdf.

Acesso em 23 mar. 2010. Link

MACEDO, Luiz Carlos de; AVERSA, Marcelo Bertini. A evolução do compromisso social das $\quad$ empresas. $2002 . \quad$ Disponível em http://www.parceirosvoluntarios.org.br/Componentes/textos/TextosVPJ.asp?txTx=39\&iRnd= 0,942\%D8. Acesso em 26 jun. 2010.Link

MAZUCHELI, Josmar; ACHCAR, Jorge Alberto. Algumas considerações em regressão não linear. Acta Scientiarum Maringá, v. 24, n. 6, 2002, p. 1761-1770. Disponível em: http://periodicos.uem.br/ojs/index.php/ActaSciTechnol/article/view/2551/1574. Acesso em 29 jun. 2010. Link

MEDEIROS, Fayrusse Correia de. Responsabilidade Social Corporativa: O Caminho da Sustentabilidade nas Empresas Competitivas. Paraíba. 2006. Disponível em: http://www.biblioteca.sebrae.com.br/bds/BDS.nsf/0166CD34CE4832BC03257219005445FC/ \$File/fayrusse.pdf. Acesso em 30 mar. 2010.Link

REUNIR - Revista de Administração, Contabilidade e Sustentabilidade - Vol. 1, nº 1, p.52-68, Mai-Ago/2011. 
MELLO NETO, Francisco P., FROES, César. Responsabilidade Social e Cidadania Empresarial. 2. ed., Rio de Janeiro: Editora Qualitymark, 2001.

MILANI FILHO, M.; CORRAR, Luiz J.; MARTINS, Gilberto A. O voluntariado nas entidades filantrópicas paulistanas: $O$ valor não registrado contabilmente. Contabilidade, Gestão e Governança, América do Norte, 6, out. 2009. Disponível em: http://www.cggamg.unb.br/index.php/contabil/article/view/200. Acesso em: 06 abr. 2010.Link

MILANI FILHO, Marco A. F. Responsabilidade Social e Investimento Social Privado: Entre o Discurso e a Evidenciação. In: Revista Contab. Fin. USP. São Paulo, v. 19, n. 47, mai/ago, 2008, pp. 89-101.

NUNES, Paulo. Conceito de Stakeholder. Disponível em: http://www.knoow.net/cienceconempr/gestao/stakeholder.htm\#vermais. Acesso em 22 mar. 2010.Link

OLIVEIRA, Braulio Alexandre C. de; GOUVÊA, Maria A.; GUAGLIARDI, Jose A. A Influência da Responsabilidade Social nas Decisões de Compra de Produtos de Conveniência. In: Anais... EnANPAD - ENCONTRO NACIONAL DOS PROGRAMAS DE PÓS-GRADUAÇÃO EM ADMINISTRAÇÃO. Curitiba, PR 25 a 29 de Setembro de 2004.

PAOLI, Maria Célia. Empresas e Responsabilidade Social: Os Enredamentos da Cidadania no Brasil. In: SANTOS, Boaventura S. (org.). Democratizar a democracia. Rio de Janeiro: Civilização Brasileira, 2002.

PELIANO, Ana Maria (org.). Bondade ou interesse? Como e por que as empresas atuam na área social. 2. ed. Brasília: IPEA, agosto de 2003.

PEROTTONI, Marco Antonio. Balanço Social: responsabilidade, padronização $e$ obrigatoriedade. Revista Brasileira de Contabilidade, ano XXXI, $\mathrm{n}^{\circ}$. 134, mar./abr. 2002, p. 51.

PINTO, Anacleto Laurino; RIBEIRO, Maisa de Souza. O Balanço Social como instrumento de evidenciação de responsabilidade social: Um estudo no estado de Santa Catarina. In: Revista Brasileira de Contabilidade, ano XXXIV, nº. 154, jul./ago. 2005, pp. 37-49.

PETERNELLI, Luiz Alexandre. Regressão Linear e Correlação, 2010. Disponível em: http://www.dpi.ufv.br/ peternelli/inf162.www.16032004/materiais/CAPITULO9.pdf. Acesso em 23 jun. 2010. Link

RESPONSABILIDADESOCIAL.COM. Balanço Social. Edição: 93 Ano: 6 ISSN: 1677-4949 Disponível em http://www.responsabilidadesocial.com/institucional/institucional_ view.php?id=4. Acesso em 06 abr. 2010. Link

REUNIR - Revista de Administração, Contabilidade e Sustentabilidade - Vol. 1, nº 1, p.52-68, Mai-Ago/2011. 
SAP BM\&FBOVESPA. Relação de Empresas que compõem e ou compuseram o ISE desde a sua criação em 2005 [mensagem pessoal]. Mensagem recebida por <sap@bvmf.com.br> em 22 jun. 2010.

SEBRAE. Práticas de responsabilidade social nas micro e pequenas empresas Bahia. Salvador: $\quad$ Bahia. $2009 . \quad$ Disponível em http://201.2.114.147/bds/BDS.nsf/3D63C892EE0B765B8325764600564E77/\$File/NT000429 CA.pdf. Acesso em: 12 abr. 2009. Link

SILVA, Carmen Luiza da.; CARVALHO, Vera. A Responsabilidade Social no Ensino Superior: $d a$ origem ao cotidiano educacional. 2008. Disponível em: http://www.abmes.org.br/NovaEstrutura/_subSites/ER2009/_downloads/Revista/2008_01_txt _Carmen_e_Vera.pdf. Acesso em: 22 mar. 2010. Link 